\title{
Secondary School Teacher Motivation, Occupational Attitudes and Job Performance in Uganda in the Context of HIV/AIDS
}

\author{
Callist Tumwebaze ${ }^{1}$ \\ ${ }^{1}$ School of Psychology, Makerere University, Kampala, Uganda \\ Correspondence: Callist Tumwebaze, School of Psychology, Makerere University, P.O.Box 7062, Kampala, Uganda. \\ E-mail: ctumwebaze@ cees.mak.ac.ug
}

Received: July 18, 2020

doi:10.5430/irhe.v5n3p26
Accepted: August 18, 2020

Online Published: October 20, 2020

URL: https://doi.org/10.5430/irhe.v5n3p26

\begin{abstract}
Secondary school teachers are a key resource for national development in Uganda. The current study explores how teachers' perceptions of HIV/AIDS impact on their motivation and occupational attitudes and how these in turn affect their job performance. Preliminary data, collected using focus group discussions, were used in the construction of the self-administered questionnaire that was completed by a geographical quota sample of 480 secondary school teachers. Multiple regression and a modified path analysis produced a model that could significantly explain multivariate relationships. It was found out that teacher perceptions of HIV/AIDS affect their work performance both directly and indirectly through their motivation and occupational attitudes. Of the four HIV/AIDS perception dimensions, infrastructural support does not have any direct or indirect effect on any of the four job performance dimensions; occupational benefit has only an indirect effect on all the four job performance dimensions and is the only one out of the four that influences moderating variables of motivation and occupational attitudes; occupational burden only affects (directly) one job performance dimension of curriculum delivery; whereas pastoral care has only a direct effect on three job performance dimensions of open-active, co-curricular, and facilitating learning. As teachers' perceptions of HIV/AIDS in Uganda influence their work motivation, attitudes and performance, occupational health interventions that promote more positive attitudes to the challenge of HIV/AIDS may have the potential to improve motivation, occupational attitudes and work performance among this crucial cadre.
\end{abstract}

Keywords: education, work, development, health, path analysis, Uganda

\section{Introduction}

Motivation is crucial for both individual and organizational performance. A motivated employee is assumed to work harder, longer, and to a higher standard than a less motivated worker (Doyle, 2003). Landy and Conte (2007) have suggested that performance is the product of motivation and ability, minus situational constraints. This paper explores how teachers' perceptions of HIV/AIDS impact on their motivation and occupational attitudes and how these in turn affect their job performance.

Motivation and performance have been extensively researched by organizational psychologists and other behavioural scientists with increasing interest in their application to low-income country settings (Carr, MacLachlan \& Furnham, 2012; MacLachlan, Carr \& McAuliffe, 2010). Work motivation is generally concerned with the factors that affect an individual's work-related attitudes and behaviour. Pinder (1984) defines work motivation as a set of energetic forces that originate both within as well as beyond an individual's being, to initiate work-related behaviour, and to determine its form, direction, intensity, and duration. This definition implies that motivation has three essential and distinct but interacting components, that is, what activities employees consciously choose to engage in (direction), how much effort they will exert in doing the chosen activities (intensity) and how persistent they are on a task (Pinder, 1984).

The Eurocentric, or 'Western' origins of most motivation theories (e.g. the content/need theories of Maslow (1954) and Herzberg (1959), McClelland's (1961) need for achievement theory, and Aldefer's ERG theory (1972)) are well recognized and cultural differences are known to be important across a range of related research, including, for instance, attributions of poverty (Campbell, Carr \& MacLachlan, 2001), international aid (MacLachlan, 1993) and health (MacLachlan, 2006). However, there remains a relative dearth of research on motivation in low-income country work contexts. Where such research does exist (Gray \& Stark, 1987; Katz, 2004, \& Doyle, 2003), it has 
primarily focused on 'Western' oriented corporations, not in public sector organizations in Africa, and particularly not on teachers.

Among the factors that may affect worker motivation and performance is HIV/AIDS. It is recognized that school teachers in sub-Saharan Africa are being and will continue to be particularly affected by the AIDS epidemic (ECA, 2000). Due to the physical and psychological effects of the epidemic, teacher morale and motivation may be adversely affected. Makuka and Kalikiti (cited in Carr-Hill, Katabaro, Katahoire, \& Oulai, 2002, p.47) neatly summarize the perceived impacts AIDS cases and death have had among teachers: "teachers become nervous and depressed, they are frequently absent, their attitudes to work deteriorate and they become unable to perform well". As such, HIV/AIDS constitutes a significant occupational health challenge in itself whilst also possibly undermining work performance.

Research indicates that the rate of HIV infection among teachers is likely to be above that for the general population in many African countries: -rates as high as 40 percent have been reported among teachers from parts of Malawi and Uganda (Coombe, 2000). The percentage of teachers who are HIV positive is deemed to be more than 30 percent in Uganda and Malawi, 20 percent in Zambia, and 12 percent in South Africa (Bakilana, Bundy, Brown, \& Fredriksen, 2005; James-Traore \& Finger, 2004).

Katahoire (1993), in an earlier study in Uganda, observed that teachers who are infected with the HIV virus may try to transfer to another area or, once visibly ill, disappear. This is due to fear of stigmatization and social exclusion both within the school and the outside community. This is attested to by Kaleeba (2008), who observed that the level of stigma in Uganda (due to HIV/AIDS) is high particularly in the north. She cited two teachers who had their names deleted from the payroll and were expelled from staff quarters after absconding from duty while on treatment. These high levels of stigma, while distressing in their own right, may also negatively affect teacher motivation and job performance.

\section{The Proposed Model}

A general structural model of teacher HIV/AIDS perceptions, motivation, occupational attitudes and job performance is proposed in Figure 1 below:

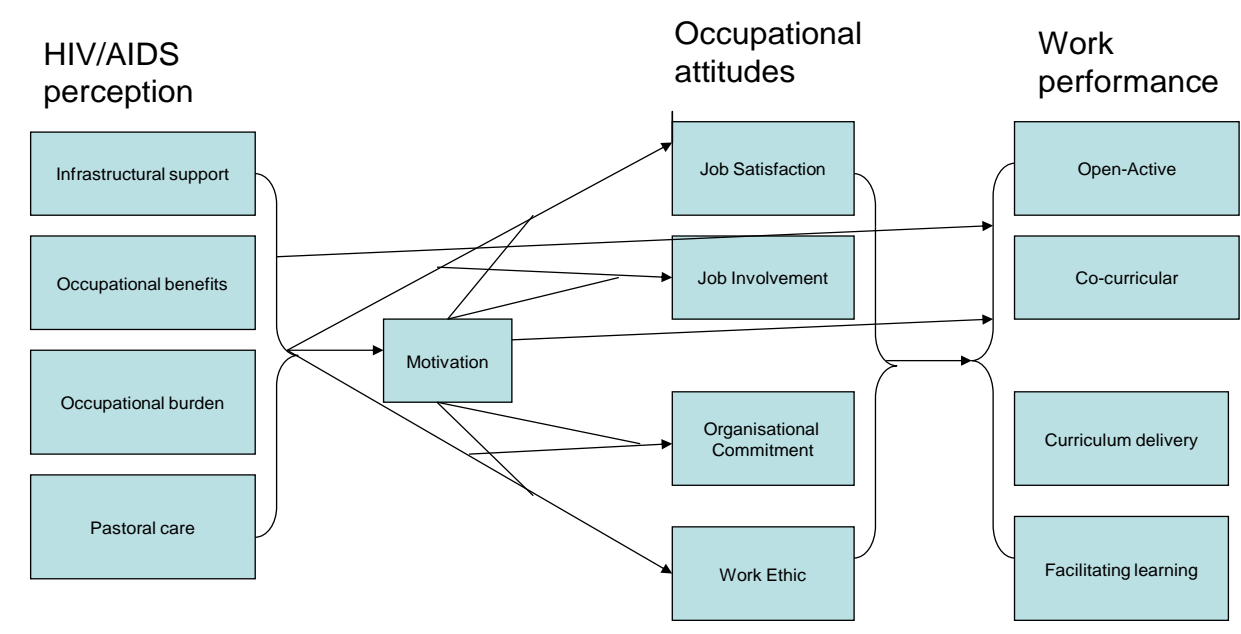

Figure 1. Input path diagram of causal relationships between HIV/AIDS perception, motivation, occupational attitudes and work performance

Figure 1 shows that the path model was specified with the four HIV/AIDS perception subscales and four job performance subscales as the exogenous and dependent variables respectively. Figure 1 shows that the path model was specified with the four HIV/AIDS perception subscales and four job performance subscales as the exogenous 
and dependent variables respectively. Following the psychometric properties of the measures (Tumwebaze, 2009), the major components of the HIV/AIDS dimension of infrastructural support were: lack of school support to HIV+ teachers, no respect in society (negative recognition), isolation and stigmatisation by the community, inadequate medical services to those infected (students, fellow teachers, parents, etc.), and students' failure attributed to teachers. The major components of the HIV/AIDS dimension of occupational benefits were: Job security, The respect and dignity associated with the teaching profession, Some fringe benefits e.g. house, water, electricity, etc., Personal survival, and Love for the profession.

The major components of the HIV/AIDS dimension of occupational burden were: Too much work as a result of taking on additional responsibilities of an absentee teacher due to HIV/AIDS, A feeling that one is teaching children who will die soon, Lower risk of infection because of working with children / teenagers, Differentiation in salaries and allowances between HIV+ and HIV- teachers, Lack of alternative employment, and Teaching HIV infected children who tend to be destructive and whose level of attention is very low.

The fourth dimension of HIV/AIDS was labelled pastoral care whose major components were: Skills of guidance and counselling and Empathy for orphaned children.

Regarding job performance, the dimension of open-active had four major components and these were: Looking for ways to make work / teaching more interesting, Seeking advice from colleagues at work, Accepting criticism / corrections in case of mistakes, Employing learner-centered teaching methods, Effective time management, Doing research / further study in my area of specialization, Maintaining rapport with students, and Dealing with problems that occur at work immediately as they occur.

The major components of the job performance dimension of co-curricular were: Participating in co-curricular activities, Attending school assemblies, Use of teaching aids, Attending and facilitating in school meetings, Attending educational workshops, and Guiding and counseling students.

The third job performance dimension was curriculum delivery and its components were: Marking and analyzing student performance and giving feedback, Updating my teaching material, Borrowing notes from students to teach, Abiding by deadlines, and Covering syllabus in time.

The fourth job performance dimension of Facilitating learning had five major components and these were: Knowing learners individually and helping them accordingly, High emotional stability in case of disappointment, Taking advantage of a conducive environment to help learners develop their potential, Availability at school for student consultations out of official school time, and targeting all possible opportunities for professional growth e.g. upgrading and attending workshops,

The self-developed model in Figure 1 suggests that teacher perceptions of the HIV/AIDS context have a direct effect on job performance. This might be because an environment where HIV/AIDS is seen as a threat is somehow felt to be less secure and supportive.

However, the model also suggests indirect effects of this perception on job performance through the mediating variables of motivation and occupational attitudes of job satisfaction, job involvement, organizational commitment and work ethic. The model further recognizes that motivation and occupational attitudes directly affect job performance.

\section{Purpose}

The researcher wished to explore the direct and indirect effect of teachers' perceptions of the HIV/AIDS context on job performance. This was based on the assumption that an environment where HIV/AIDS is seen as a threat is, somehow, felt to be less secure and supportive and that this, in turn, might affect work performance directly or indirectly through motivation and occupational attitudes.

\section{Method}

\subsection{Participants and Procedure}

Secondary school teachers were drawn from two out of the four regions of the country, that is, Central and South-west. The choice of these regions was based on their easy accessibility to the researcher and the fact that they have been reported to have comparatively higher rates of HIV/AIDS infection. From each region, 10 government schools and 10 privately owned schools were selected using simple random sampling, making a total of 40 schools (The researcher aimed at balancing the number of rural and urban schools). This sampling technique was deemed to be appropriate because it was easy for the researcher to obtain lists of all government and privately owned schools from the regional education offices from where the required representative number of schools was selected. Data 
were collected from a questionnaire survey with a random probability sample of 480 teachers. The author, with the help of research assistants, went to each school and requested permission from the school administrator to access teachers for a questionnaire survey.

From each school, 12 teachers were selected by the researcher using simple random sampling. The researcher visited each school during break or lunch time so as to find "all" teachers in the staff room. He assigned unique random numbers to the teachers and then using the lottery method, the selected teachers were included in the sample. After briefing the teachers about the purpose of the study, the ethical considerations involved, the questionnaire structure and the response format, the researcher/research assistant gave out the questionnaires to the selected respondents. Respondents were requested to return the filled-in questionnaires (sealed in the envelopes provided to them by the researcher) to the school Administrative Secretary, from whom the researcher collected them the next day or thereafter. Out of the 480 questionnaires given out, 410 (85\%) were returned. The demographic characteristics of the participants are presented in Table 1:

\subsection{Instruments}

A self-administered questionnaire containing eight sections was used to collect data from teachers

Section A measured respondents' Background information; Section B measured teachers' level of motivation. It used a 23- item scale adapted from Spence and Helmreich (1983) and modified; Section C had 19 self-constructed items which required respondents to rate the extent to which the HIV/AIDS work environment factors impact their work; Section D measured respondents' job satisfaction on a 26 item scale most of which were adapted from the overall job satisfaction scale (Warr, Cook, \& Wall, 1979) and Minnesota Satisfaction Questionnaire (Weiss, Dawis, England, \& Lofquist, as cited in Cook, Hepworth, Wall \& Warr, 1981) and modified ;

Section E had a measure of job involvement with 16 items most of which were adapted from the scale by Lodahl and Kejner (cited in Cook et al. 1981) and modified; Section F comprised the 22-item organisational commitment scale with most items adapted from the existing standardized Organisational Commitment Questionnaire (Porter and Smith, as cited in Cook, et al. 1981) and modified ; Section G had the 21-item protestant work ethic measure with most of the items adapted from the Mirels and Garrett's (cited in Cook, et al. 1981) protestant ethic scale and modified; and Section $\mathrm{H}$ was a 28 self-constructed job performance scale.

\subsection{Data Analysis}

Data was edited, coded and entered into the computer and cleaned. Preliminary analysis was done using frequencies procedures. Advanced analysis was dome using path analysis.

\section{Findings}

Findings are presented beginning with preliminary analysis results. See Tables 1 and 2.

Table 1. Demographic characteristics $(\mathrm{N}=410)$

\begin{tabular}{lll}
\hline Variable & N & Percentage \\
\hline Gender & & \\
\hline Male & 244 & 60 \\
\hline Female & 163 & 40 \\
\hline Age & & \\
\hline Below 25 & 48 & 11.8 \\
\hline $25-29$ & 127 & 31.1 \\
\hline $30-34$ & 96 & 23.5 \\
\hline $35-39$ & 55 & 13.5 \\
\hline $40-44$ & 50 & 12.3 \\
\hline $45-49$ & 27 & 6.6 \\
\hline 50 and above & 5 & 1.2 \\
\hline Education level & & \\
\hline Senior six leaver & 1 & .2 \\
\hline Diploma & 91 & 22.3 \\
\hline
\end{tabular}




\begin{tabular}{lll}
\hline Bachelor's degree & 264 & 64.7 \\
\hline Masters' degree & 52 & 12.7 \\
\hline Years of teaching & & \\
\hline Below three & 86 & 21.1 \\
\hline $3-5$ & 116 & 28.4 \\
\hline $6-8$ & 71 & 17.4 \\
\hline $9-11$ & 37 & 9.1 \\
\hline 12 and above & 98 & 24.0 \\
\hline Type of school & & \\
\hline Government & 211 & 52.1 \\
\hline Private & 194 & 47.9 \\
\hline School location & & \\
\hline Urban & 206 & 50.5 \\
\hline Rural & 202 & 49.5 \\
\hline Nature of school & & \\
\hline Single Boys & 13 & 3.2 \\
\hline Single Girls & 47 & 11.5 \\
\hline Mixed & 349 & 85.3 \\
\hline
\end{tabular}

From Table 1 above, the modal age range was 25-29 (31.1\%), followed by 30-34 (23.5\%) with the lowest being 50 years and above (1.2\%). 60\% of the respondents were males and $40 \%$ females. In terms of their educational qualifications, $64.7 \%$ had a Bachelor's degree, $22.3 \%$ had a diploma and $12.7 \%$ had a Masters degree. $52.1 \%$ of the respondents were teaching in government schools compared to $47.9 \%$ in private schools. In terms of school location, half $(50.5 \%)$ were teaching in urban schools and half $(49.5 \%)$ in rural school.

Table 2. The Scales and subscales used in the study

\begin{tabular}{llll}
\hline Scale & Subscale & Alpha & \% variance explained \\
\hline Motivation & & .78 & 40.70 \\
\hline HIV/AIDS perception & Infrastructural support & .80 & 17.24 \\
\hline & Occupational benefit & .69 & 11.99 \\
\hline & Occupational burden & .61 & 11.46 \\
\hline Job Satisfaction & Pastoral care & .51 & 8.64 \\
\hline Job Involvement & & .90 & 59.37 \\
\hline Organisational commitment & & .77 & 35.91 \\
\hline Work Ethic & & .80 & 48.31 \\
\hline Job Performance & Open-Active & .65 & 34.55 \\
\hline & Co-curricular & .77 & 12.40 \\
\hline & Curriculum delivery & .76 & 11.59 \\
\hline & Facilitating learning & .68 & 10.11 \\
\hline
\end{tabular}


As shown in Table 2, unlike the motivation, job satisfaction, job involvement, organizational commitment and work ethic scales whose total scale scores were considered in the analysis, teachers' perceptions of HIV/AIDS and Job performance scales were presented with their sub-scale total scores given that the items on the scales were not additive. The coefficient alphas for all the scales/sub-scales were high enough to be considered for analysis and the percentage variance explained by each scale/sub-scale is also presented in the Table 2. (See Tumwebaze, 2009, for further details of the psychometric properties of the scales and subscales).

\subsection{Advanced Data Analysis Results}

Path analysis was conducted using Mplus to establish the direct and indirect effects of the variables and to test the proposed general structural model of teacher HIV/AIDS perceptions, motivation, occupational attitudes and job performance is proposed in Figure 1 above:

In order to summarize how the sample differed in their scores on different questionnaires, the means and standard deviations of the total scores for each variable were computed and the results are presented in Table 3.

Table 3. The descriptive statistics for the study variables

\begin{tabular}{lllllll}
\hline Scale & Subscale & $\mathrm{N}$ & Range & Mean & SD & Variance \\
\hline Motivation & & 327 & 71.00 & 70.66 & 8.10 & 65.57 \\
\hline $\begin{array}{l}\text { HIV/AIDS } \\
\text { perception }\end{array}$ & Infrastructural support & 297 & 20.00 & 12.64 & 5.12 & 26.23 \\
\hline & Occupational benefit & 388 & 18.00 & 21.11 & 3.28 & 10.76 \\
\hline & Occupational burden & 378 & 16.00 & 11.64 & 3.75 & 14.09 \\
\hline & Pastoral care & 381 & 8.00 & 8.61 & 1.34 & 1.80 \\
\hline Job Satisfaction & & 336 & 58.00 & 46.51 & 12.03 & 144.79 \\
\hline Job Involvement & & 372 & 45.00 & 51.43 & 6.89 & 47.50 \\
\hline $\begin{array}{l}\text { Organisational } \\
\text { commitment }\end{array}$ & 335 & 52.00 & 63.25 & 9.48 & 89.93 \\
\hline Work Ethic & & 334 & 43.00 & 64.25 & 7.38 & 54.51 \\
\hline Job Performance & Open-Active & 367 & 23.00 & 32.52 & 4.36 & 18.99 \\
\hline & Co-curricular & 372 & 20.00 & 22.57 & 4.02 & 16.20 \\
\hline & Curriculum delivery & 380 & 12.00 & 16.98 & 2.51 & 6.28 \\
\hline & Facilitating learning & 381 & 20.00 & 18.93 & 3.18 & 10.10 \\
\hline
\end{tabular}

As can be seen in Table 3, the number of participants that responded varied for the seven variables measured.

The analysis for the model in Figure 1 was conducted using MPlus version 4.21. It was based on co-variances estimated using maximum likelihood. The significant standardized coefficients are presented in Figure 2: 


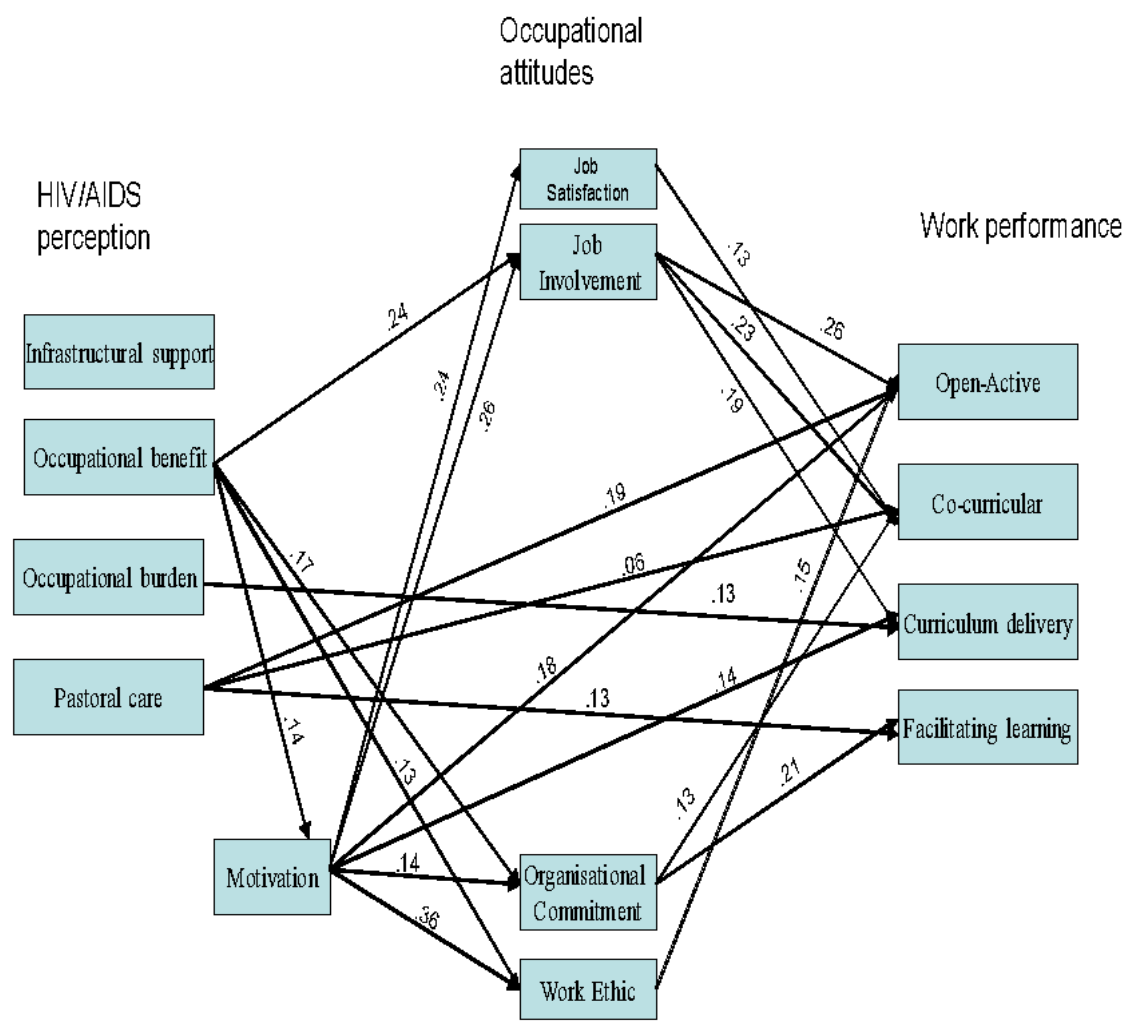

Figure 2. Standardised regression coefficients between HIV/AIDS perception, motivation, occupational attitudes and job performance

Note: Only significant coefficients are shown.

As shown in Figure 2, the HIV/AIDS perception facet of infrastructural support was not associated with any variable. Motivation was associated with job satisfaction $(r=.24)$ and job involvement $(r=-0.26)$. Occupational benefit was associated with motivation $(\mathrm{r}=.14)$. Motivation was associated with organisational commitment $(\mathrm{r}=.14)$, and motivation was associated with work ethic $(r=.36)$.

Direct and indirect significant predictors facets of work performance

1. Open-active facet

(a) Open active was predicted by pastoral care $(\mathrm{r}=.19)$

(b) Indirect predictors were occupational benefit through job involvement $(\mathrm{r}=.26)$; occupational benefit through work ethic $(\mathrm{r}=.15)$ and occupational benefit through motivation and work ethic

2. Co-curricular facet

(a) Co-curricular facet was predicted directly by pastoral care $(\mathrm{r}=.06)$.

(b) Indirect paths were from occupational benefit to job involvement $(r=.24)$ and to co-curricular $(r=.23)$ and from occupational benefit to motivation $(\mathrm{r}=.14)$ and to organisational commitment to co-curricular $(\mathrm{r}=.13)$

3. Curriculum delivery facet

(a) This facet was directly predicted by occupational burden $\mathrm{r}=.13$

(b) There were 2 indirect paths. From occupational benefit to job involvement $r=24$, to job involvement and curriculum delivery $(r=19)$. Another indirect path was from occupational benefit to motivation and to curriculum delivery $(\mathrm{r}=.14$ and $\mathrm{r}=.14$ respectively)

4. Facilitating learning facet 
(a) This facet had a direct path with pastoral care $(\mathrm{r}=.13)$

(b) There was an indirect line from occupational benefit to motivation $(\mathrm{r}=.14)$ and from motivation to organisational committeemen $(\mathrm{r}=.14)$ and from organisational commitment to facilitating learning $(\mathrm{r}=.21)$

The largest direct effect on job performance 1 (Open-Active) was job involvement (.26) followed by pastoral care (.19). The other direct effects were motivation (.18) and work ethic (.15). For job performance 2 (co-curricular), job involvement was also the largest direct effect (.23), followed by job satisfaction (.13) and organizational commitment (.13) with the smallest being pastoral care (.06). Job performance 3 (curriculum delivery) also had job involvement with the largest direct effect (.19), the other two being motivation (.14) and occupational burden (.13). Job performance 4 (facilitating learning) had only 2 direct effects of organizational commitment (.21) and pastoral care (.13).

Of the four HIV/AIDS perception dimensions, infrastructural support does not have any direct or indirect effect on any of the four job performance dimensions; occupational benefits has only indirect effect on all the four job performance dimensions and is the only one out of the four that influences moderating variables of motivation and occupational attitudes; occupational burden only affects (directly) one job performance dimension of curriculum delivery (.13); whereas pastoral care has only a direct effect on three job performance dimensions of open-active (.19), co-curricular (.06), and facilitating learning (.13).

\section{Discussion}

Teacher HIV/AIDS perceptions, Motivation, Occupational attitudes and Work performance

The emergent model suggests that there are three distinct mechanisms through which teachers' perceptions of the HIV/AIDS context affect their job performance. The dimension of HIV/AIDS of "pastoral care" directly affects three out of four job performance dimensions (open-active, co-curricular, and facilitating learning), "occupational burden" directly affects the job performance dimension of curriculum delivery, whereas "occupational benefits" indirectly affects all the four job performance dimensions indirectly through the mediating variables of motivation, job involvement, organizational commitment, and work ethic.

These relational mechanisms make rational sense in that teachers who perceive the HIV/AIDS environment as occupationally beneficial through greater social support or providing opportunities related to, also show higher work motivation whereas those who do not have such feelings and do not envisage much occupational benefit arising out of the HIV context are less motivated to work. Teachers with high levels of motivation will be actively involved in the actual teaching, co-curricular activities and will do all they can to facilitate the teaching-learning process.

The dimension of HIV/AIDS perception of "occupational burden" was negatively related to motivation and curriculum delivery (teacher's actual teaching ability or delivery of subject matter). This also makes sense in that teachers who see working in the context of HIV/AIDS as burdensome will have less motivation to work. This may arise because they are given extra workload as a result of absent teachers who may be sick or attending to sick relatives or funerals. Furthermore, once teachers know that they are HIV positive, they may lose interest in continuing professional development and when they develop full-blown AIDS, their work will likely be seriously compromised by prolonged periods of illness, when they will also be facing being stigmatized not only from the community, but also from their own schools/institutions as well (Coombe, 2004). However, the impact is not only felt by those who are HIV+; even among teachers who believe they are not infected (or, perhaps, simply do not want to be tested), morale is likely to fall significantly. They are required to cope both emotionally and financially with sickness and death among relatives, friends and colleagues, and struggle with the uncertainty regarding their own future and that of their dependants.

Coombe (2004) also observes that the HIV/AIDS-related stigmatization is responsible for social rejection, alienation, and can compromise employment, housing, schooling and childcare. There is evidence that a number of employees have lost their job as a result of being HIV positive (Henry, Penalba, Beguinot, \& Deschamps, 1999) and that AIDS patients are less likely to be employed (Leigh, Lubeck, Farnham, \& Fries, 1995). This may point to the fact that employees, with or without AIDS, will live in constant fear of being terminated from their jobs and this consequently affects their motivation and actual performance.

In a school setting, the fear of stigmatization may be particularly strong among teachers who live and work in rural areas or small communities, where confidentiality is problematic. This could further explain why HIV/AIDS dimension of infrastructural support does not have any effect on any of the job performance facets. Teachers who are affected by HIV/AIDS cannot openly reveal the lack of support from the government or their schools as this could put their jobs in jeopardy. They only have to bear the effects in silence. 
From the numerous studies available (Kaleeba, 2008; Katahoire, 1993; Coombe, 2004; Deschamps, 1999 \& Fries, 1995), therefore, it can be concluded that due to the devastating physical and psychological effects of HIV/AIDS on the victim's health, these people will likely develop unfavourable attitudes to work, with very low motivation and this will adversely affect their performance.

\section{Conclusions}

The theoretical model that HIV/AIDS perception influences motivation and occupational attitudes; which in turn influence work performance among teachers seem to have found support. The study has demonstrated that teachers who perceive the HIV/AIDS context as threatening and burdensome have low motivation to work and their ability to deliver content is affected due to the physical and psychological effects of the disease on their health. They simply "force themselves" in the classroom but they may not perform to the expected standards as their attention and concern is directed more towards their health and those under their care. Some may be required to take on additional work load/responsibilities of an absentee teacher due to HIV/AIDS.

The HIV/AIDS burden is also felt through illness of teachers and/or their family members and through the needs of students who are ill or who have ill family members. However, due to fear of social isolation, stigmatization and rejection coupled with lack of support in and from the school and the community, teachers who are HIV positive prefer to keep quiet and suffer silently. In their silence, they are able to continue teaching in order to maintain their jobs and thus enjoy the related occupational benefits for example housing, allowances and the respect that is generally accorded to teachers. This is demonstrated in the study finding that the dimension of HIV/AIDS of occupational benefits indirectly affects all aspects of teaching, that is, open-active, co-curricular, curriculum delivery and facilitation of learning.

\section{Recommendations}

In the light of the above conclusions, there is need for government to improve job performance in the era of high prevalence of HIV/AIDS by addressing the following areas:

1. To improve open-active, there is need to promote job involvement, pastoral care, motivation and work ethic.

Job involvement refers to the psychological and emotional extent to which some one participates in his/her work, profession, and company. Many ways exist for involving employees/teachers in their jobs. Participation in decision making is one of them where teachers are allowed to participate in decisions that affect them as they execute their duties.

This can be achieved by providing pastoral care that involves counselling; provision of incentives including money in order to improve both their intrinsic and extrinsic motivation. Work ethics should be promoted by training teachers in professional ethics. This will boost the work culture and interpersonal communication

There is also need for the government and the schools to put in place programmes meant to mitigate the effects of HIV/AIDS on the members of the school community. Such programmes would be geared towards encouraging those affected by the disease to seek mutual support, speak out, and play for a leadership role in demanding changed behaviour; encouraging changed sexual behaviour among teachers, students, and community members;

The government, through the Ministry of Education and Sports, should also establish the position of school counsellor in every school and ensure that it is held by a trained/professional person who will provide support to members of the school community, including teachers and students, who may be affected by HIV/AIDS and any other problems that require counselling.

2. To improve co-curricular, there is need to promote job involvement, motivation, pastoral care and organisational commitment

Having adequate supplies of anti-retroviral drugs for those who are HIV positive and providing them with financial support. This will make them feel proud to belong to their schools, raise their respect and dignity in the community. It will also promote their commitment to their profession and schools, raise their motivation to work and subsequently improve their performance.

It is also recommended that the government and schools should provide teachers with skills of guidance and counselling so as to equip them with the necessary knowledge/skills to support their colleagues and students affected by HIV/AIDS.

3. To improve curriculum delivery, there is need for the government to improve job involvement, lessen occupational burden and improve motivation. 
Since occupational benefits affect basically all aspects of teaching, the government, through the Ministry of Education and Sports, and school management should endeavour to provide teachers with such necessities as decent housing, water, and electricity. This will boost their motivation.

4. To improve facilitating learning, there is need to step up organisational commitment and pastoral care.

In the event of a teacher being absent due to HIV/AIDS-related causes, schools should arrange lesson covers in such a way that teachers covering lessons are not too overloaded and they should also be paid for the extra work load.

\section{Further research}

Given that the current study randomly selected participants, future research might explore the possibility of a study that purposively draws a sample of HIV positive and HIV negative teachers with the view of comparing their levels of motivation and job performance. This is due to the conclusion drawn from the current study that the impact of HIV is felt individually-it is likely that the majority of teachers that participated in the current study were HIV negative and thus may not have perceived HIV/AIDS in their work environment as a threat to their motivation and performance.

A study of the impact of HIV/AIDS on teacher motivation and performance could be conducted in districts with high prevalence rates of HIV. Data for the prevalence rates could be obtained from the National Bureau of Statistics. Teachers in such contexts may have experienced the effects of HIV/AIDS more and may be much freer and open to talk about HIV/AIDS issues than teachers in the current study. Thus, such a study would provide a more realistic picture of the effects of HIV/AIDS on teacher motivation, occupational attitudes and performance.

\section{References}

Alderfer, C. P. (1972). Existence, Relatedness, and Growth: Human needs in organizational settings. New York: The Free Press.

Bakilana, A., Bundy, D., Brown., \& Fredriksen, B. (2005). Accelerating the Education Sector Response to HIV/AIDS in Africa: A Review of World Bank Assistance. World Bank Global HIV/AIDS Program Discussion Paper. World Bank: Washington, D.C. Retrieved from www.worldbank.org/AIDS

Campbell, D., Carr, S. C., \& MacLachlan, M. (2001). Attributing “Third World" poverty in Australia and Malawi: A case of Donor Bias?. Journal of Applied Social Psychology, 31, 409-430.

Carr, S. C., MacLachlan, M., \& Furnham, A. (2012) Humanitarian Work Psychology. London: Palgrave.

Carr-Hill, R., Katabaro, K. J., Katahoire, A. R., \& Oulai, D. (2002). The Impact of HIVIAIDS on education and institutionalizing preventive education. Paris: International Institute for Educational Planning/UNESCO.

Cook, J. D., Hepworth, S. J., Wall, T. D., \& Warr, P. B. (1981). The Experience of Work: A Compendium and Review of 249 Measures and their use. London: Academic Press.

Coombe, C. (2000). HIV/AIDS and the Education sector: The foundations of control and management strategy in South Africa. Pretoria. Unpublished paper.

Coombe, C. (2004). Confronting the Impact of HIV/AIDS: the consequences of the pandemics for education supply and demand. A global review from a South African perspective. Policy Features in Education, 2(1), 102-140.

Doyle, C. E. (2003). Work and Organizational Psychology: An Introduction with attitude. Hove and New York: Psychology Press.

Economic Commission for Africa (ECA). (2000). HIV/AIDS and Education in Eastern and Southern Africa: the leadership challenge and the way forward. A paper for the African Development Forum. Addis Ababa. Ethiopia.

Gray, J. L., \& Stark, F. A. (1984). Organisational behaviour concepts and applications (3rd ed.). Columbus Ohio: Charles E. Merrill Publishing Co.

Henry, L. V., Penalba, C., Beguinot, I., \& Deschamps, C. (1999). Relationships between work and HIV/AIDS status. Occupational Medicine, 49, 115-116.

Herzberg, F. (1959). The motivation to work (2nd ed.). New York: John Wiley \& Sons.

James-Traore, T. A., \& Finger, W. (2004). Teacher Training: Essential for School-Based Reproductive Health and HIV/AIDS Education-Focus on sub-Saharan Africa. Youth Issues, Paper 3. Family Health International, YouthNet. 
Kaleeba, N. (2008). Uganda: Stigma, discrimination holding back HIV fight. Article in The Eastern Africa AIDSPortal Network Information. Retrieved from http://www.plusnews.org/Report.aspx?ReportId=80471

Katahoire, A. (1993). The Impact of AIDS on Education in Uganda: A case study of Lyantonde Community. Kampala International Development Research Centre. Unpublished.

Katz, P. (2004). The human side of managing technological innovation (2nd ed.). New York: Oxford.

Landy, F. J., \& Conte, J. M. (2007). Work in the 20 $0^{\text {th }}$ century: An Introduction to Industrial and Organizational Psychology (2nd ed.). Blackwell.

Leigh, J. P., Lubeck, D. P., Farnham, P. G., \& Fries, J. F. (1995). Hours at work and employment status among HIVinfected patients. AIDS, 9(1), 81-88.

MacLachlan, M. (1993). Sustaining Human Resource Developments in Africa: The influence of Expatriates. Management Education and Development, 24(2), 167-171.

MacLachlan, M. (2006). Culture and Health: A Critical Perspective towards Global Health (2nd ed.). Chichester: Wiley.

MacLachlan, M., Carr, S. C., \& McAuliffe, E. (2010). The Aid Triangle: Recognizing the Human Dynamics of Dominance, Justice and Identity. London: Zed Books.

Maslow, A. (1954). Motivation and Personality (1st ed.). New York: Harper.

McClelland, D. C. (1961). The Achieving Society. Princeton, NJ: Van Nostrand.

Pinder, C. C. (1984). Work Motivation: Theory, Issues, and Applications. Glenview, IL: Scott, Foresman, \& Company.

Spence, J. A., \& Helmreich, R. L. (1983). Achievement related motives and behaviour. In J. T. Spence (Ed.), Achievement and achievement motives. San Francisco: W.H. Freeman.

Tumwebaze, C. (2009). An Exploratory Study into Secondary School Teacher Motivation, Occupational Attitudes and Job Performance in Uganda in the in the Context of HIV/AIDS. An Unpublished Doctoral Thesis, Trinity College Dublin, Ireland.

Warr, P. B., Cook, J., \& Wall, T. D. (1979). Scales for the measurement of some work attitudes and aspects of psychological well-being. Journal of Occupational Psychology, 52, 129-148.

\section{Copyrights}

Copyright for this article is retained by the author(s), with first publication rights granted to the journal.

This is an open-access article distributed under the terms and conditions of the Creative Commons Attribution license (http://creativecommons.org/licenses/by/4.0/). 